\title{
Does foreign sector help forecast domestic variables in DSGE models?*
}

\author{
Marcin Kolasa ${ }^{\dagger} \quad$ Michał Rubaszek ${ }^{\ddagger}$ \\ PRELIMINARY
}

\begin{abstract}
This paper evaluates the forecasting performance of several variants of a standard small open economy DSGE model relative to a closed economy benchmark using a long span of data for Australia, Canada and the United Kingdom. We find that accounting for a foreign sector in the model does not improve, and usually even deteriorates, the quality of point and density forecasts for key domestic variables. We show that this result can be at least partially attributed to an increase in forecast error due to a more sophisticated structure of the extended setup. This claim is based on a Monte Carlo experiment, in which an open economy model fails to consistently beat its closed economy benchmark even if it is the true data generating process.
\end{abstract}

JEL: D58, E17, F41, F47

Keywords: Forecasting, DSGE models, New Open Economy Macroeconomics, Bayesian estimation

\section{Introduction}

Estimated dynamic stochastic general equilibrium (DSGE) models are currently a benchmark tool used around the world for policy analysis and forecasting, especially in central banks and international financial institutions. Arguably, one of the key drivers behind this trend has been the growing evidence that DSGE model-based forecasts can be competitive with predictions obtained from flexible time series models such as vector autoregressions (VAR)

*This project was financed by the National Science Centre grant No.2012/07/E/HS4/01080. The usual disclaimer applies.

†Warsaw School of Economics and Narodowy Bank Polski; Email: marcin.kolasa@sgh.waw.pl.

†Warsaw School of Economics and Narodowy Bank Polski; Email: michal.rubaszek@sgh.waw.pl. 
or elaborated by experts (see Del Negro and Schorfheide, 2012, for a survey). It should be emphasized, however, that the vast majority of studies evaluating the forecasting performance of DSGE models focus on the US economy and assume a closed economy setup. Research using the New Open Macroeconomics (NOEM) framework, originating from Obstfeld and Rogoff (1995) and later extended by Devereux and Engel (2003) and Gali and Monacelli (2005), is relatively scarce and usually based on a relatively short forecast evaluation sample. The earliest contribution to this literature is Bergin (2003), who tests in-sample performance of small open economy DSGE models for Australia, Canada and the United Kingdom, and Bergin (2006), where a two-country model for the US and G7 is considered (also in-sample). To our knowledge there are only few studies that focus on the out-of-sample performance of NOEM models, including: Adolfson et al. (2007a) and Christoffel et al. (2010) for the euro area, Adolfson et al. (2008) for Sweden, Matheson (2010) for Australia, Canada and New Zealand, Gupta and Kabundi (2010) and Alpanda et al. (2011) for South Africa, and Marcellino and Rychalovska (2014) for Luxemburg within the euro area. In all these papers the common practice is to compare forecasts generated with a NOEM framework to those obtained with some variants of Bayesian VARs. The overall finding is that open economy DSGE models are quite competitive, even though the conclusions differ by variables and countries. However, the literature is silent about how much we really gain by accounting for an external block in DSGE models.

We claim that this issue is relevant for several reasons. First, if the only aim is to produce accurate forecasts, the use of a NOEM model might not be cost efficient ast the forecasts it generates may be not competitive in comparison to a closed economy benchmark. Second, there are reasons to be sceptical about the empirical success of the NOEM framework. In an influential paper Justiniano and Preston (2010a) demonstrate that an estimated small open economy DSGE model fails to account for the substantial influence of foreign shocks on domestic variables that can be identified in many reduced-form studies. They show that capturing the observed co-movement between domestic and foreign macroindicators generates counterfactual implications for other variables, especially for the real exchange rate and terms of trade, which complicates estimation of the model parameters. Third, it is also well-known that NOEM models have difficulty in explaining swings in exchange rates and current account balances (Engel, 2014; Gourinchas and Rey, 2014), which might distort the indirect impact of foreign variables on the domestic economy. Along these lines, Ca' Zorzi et al. (2016) have recently shown that forecasts of real exchange rates (but not of nominal exchange rates) obtained from open economy DSGE models are competitive with the random walk.

In this paper we evaluate the forecasting performance of a state-of-the-art NOEM model developed by Justiniano and Preston (2010b) relative to its associated small-scale New Key- 
nesian (NK) closed economy benchmark. We focus on the forecast accuracy for three key domestic macrovariables showing up in all models: output, consumer prices and the shortterm interest rate. As regards the NOEM framework, we consider several variants that differ by the subset of foreign sector variables that are used in estimation. These variables are: the real exchange rate, terms of trade, current account balance, as well as foreign output, inflation and interest rates. Our conclusions are based on evidence from three economies, i.e. Australia, Canada and the United Kingdom, for which we can collect data that go back to year 1975. This allows us to use the evaluation sample that is much longer compared to the previous studies.

The main results of our forecasting contest indicate that accounting for the foreign sector is not crucial for out-of-sample performance of DSGE models. When we consider the largest NOEM model, its point and density forecasts for domestic variables are statistically indistinguishable from, or even in many cases significantly less accurate than, those produced by the closed-economy benchmark. Alternative NOEM model variants that leave either terms of trade or both terms of trade and foreign variables unobservable do not perform better: they also do not improve forecasts quality relative to the closed economy variant. Next, we explore whether this disappointing NOEM model performance can be attributed to misspecification or rather the fact that bigger models are subject to a larger estimation error. For that purpose we performed a comparable forecasting competition using Bayesian VAR models and found that expanding their dimension to include external sector variables does not lead to any systematic improvement in the quality of forecasts, which is in contrast to the Large Bayesian VAR literature (Banbura et al., 2010).

We also conduct a Monte Carlo experiment to show that the NOEM model fails to consistently beat the closed-economy DSGE benchmark even if it is the true data generating process and the prior is correctly specified. More precisely, we generate artificial data from an open economy DSGE model with parameters fixed at their prior means to find that, even if the NOEM framework is not misspecified, we should not expect it to generate forecasts that are of significantly higher quality than those obtained from a simple closed economy setup. The above findings would suggest that, even if the NOEM model is a correct model, a strategy to ignore the external sector while using DSGE models to forecast domestic variables can be justified.

The rest of this paper is structured as follows. Section 2 presents the benchmark NOEM model and its closed economy counterpart. Section 3 discusses the links between foreign sector and domestic variables implied by the theory underlying the NOEM model structure. Section 4 describes the data and estimation issues. The design of our forecasting test, its main results for Australia, Canada and the United Kingdom, as well as the outcomes of a 
Monte Carlo experiment are presented in section 5. Section 6 concludes.

\section{Models}

\section{$2.1 \quad$ Full NOEM model}

The full NOEM model is based on the setup proposed by Justiniano and Preston (2010b), which is a generalization of the simple small open economy framework of Gali and Monacelli (2005). In this model households maximize their utility over consumption and labor, which is the only input to production. The consumption good is a composite of goods produced domestically and imported from abroad. Both domestic producers and importers operate in a monopolistically competitive environment and set their prices in a staggered fashion. The monetary authority sets the nominal interest rate according to a generalized Taylor rule. The foreign economy is modelled as exogenous to the domestic economy.

The model includes a set of nominal and real rigidities that are usually considered in the empirical DSGE literature (Christiano et al., 2005; Smets and Wouters, 2007), also in the open economy context (Adolfson et al., 2007a). There are habits in consumption and prices of non-optimizing firms are partially indexed to past inflation. Imports are priced in the local currency, which allows for short-run deviations from the law of one price. International financial markets are assumed to be incomplete. The model's stochastic structure is also fairly rich as it includes shocks to productivity, import markups, household preferences, international risk premium, current account balance and monetary policy, as well as disturbances driving output, inflation and the interest rate abroad.

A detailed description of problems faced by agents populating the model economy can be found in Justiniano and Preston (2010b). Below we only present the full set of log-linearized equations characterizing the equilibrium. In what follows, all variables are expressed as logdeviations from the non-stochastic steady state. Variables with asterisk refer to the foreign economy.

Household optimization leads to the Euler equation

$$
c_{t}=\frac{1}{1+h} \mathbb{E}_{t} c_{t+1}+\frac{h}{1+h} c_{t-1}-\frac{1-h}{\sigma(1+h)}\left(i_{t}-\mathbb{E}_{t} \pi_{t+1}-g_{t}+\mathbb{E}_{t} g_{t+1}\right),
$$

in which $c_{t}$ denotes consumption, $i_{t}$ is the nominal iterest rate, $g_{t}$ stands for the preference shock, $h$ describes the degree of external habits and $\sigma$ represents the inverse of the intertemporal elasticity of substitution. CPI inflation $\pi_{t}$ is defined as a weighted average of domestically produced and imported goods inflation $\pi_{H, t}$ and $\pi_{F, t}$ 


$$
\pi_{t}=(1-\alpha) \pi_{H, t}+\alpha \pi_{F, t},
$$

where $\alpha$ is the share of imports in domestic demand.

The market clearing condition can be written as

$$
y_{t}=(1-\alpha) c_{t}+\alpha y_{t}^{*}+\alpha \eta\left(s_{t}+q_{t}\right),
$$

where $y_{t}$ and $y_{t}^{*}$ denote domestic and foreign output, $q_{t}$ is the (CPI-based) real exchange rate, $\eta$ denotes the elasticity of substitution between domestic and foreign goods, and $s_{t}$ is the terms of trade defined as the price ratio of imports and goods produced domestically so that

$$
s_{t}=s_{t-1}+\pi_{F, t}-\pi_{H, t} .
$$

The Phillips curves for prices of domestic and imported goods are

$$
\begin{gathered}
\pi_{H, t}=\frac{\beta}{1+\beta \delta_{H}} \mathbb{E}_{t} \pi_{H, t+1}+\frac{\delta_{H}}{1+\beta \delta_{H}} \pi_{H, t-1}+\frac{\left(1-\theta_{H}\right)\left(1-\beta \theta_{H}\right)}{\theta_{H}\left(1+\beta \delta_{H}\right)} m c_{t} \\
\pi_{F, t}=\frac{\beta}{1+\beta \delta_{F}} \mathbb{E}_{t} \pi_{F, t+1}+\frac{\delta_{F}}{1+\beta \delta_{F}} \pi_{F, t-1}+\frac{\left(1-\theta_{F}\right)\left(1-\beta \theta_{F}\right)}{\theta_{F}\left(1+\beta \delta_{F}\right)}\left(q_{t}-(1-\alpha) s_{t}\right)+c p_{t},
\end{gathered}
$$

where $\theta_{H}$ and $\theta_{F}$ are the Calvo probabilities, $\delta_{H}$ and $\delta_{F}$ denote the degree of indexation for prices of domestic and imported goods, $\beta$ is households' subjective discount factor and $c p_{t}$ is a cost-push shock in the import sector. Domestic marginal cost $m c_{t}$ is given by

$$
m c_{t}=\varphi y_{t}-(1+\varphi) z_{t}+\alpha s_{t}+\frac{\sigma}{1-h}\left(c_{t}-h c_{t-1}\right),
$$

where $z_{t}$ denotes a productivity shock and $\varphi$ stands for the inverse of the Frisch elasticity of labor supply.

The dynamics of the real exchange rate is governed by the uncovered interest rate parity (UIP) extended for risk premium

$$
\left(i_{t}-E_{t} \pi_{t+1}\right)-\left(i_{t}^{*}-E_{t} \pi_{t+1}^{*}\right)=\mathbb{E}_{t} q_{t+1}-q_{t}-\chi a_{t}-\phi_{t},
$$

where $\pi_{t}^{*}$ is foreign inflation, $i_{t}^{*}$ denotes foreign interest rate, $\phi_{t}$ is a risk premium shock and $\chi$ is the risk premium elasticity with respect to the net foreign assets position $a_{t}$. The law of motion for $a_{t}$ is

$$
a_{t}=\frac{1}{\beta} a_{t-1}+c a_{t},
$$


with the current account balance (expressed relative to output) defined as

$$
c a_{t}=y_{t}-c_{t}-\alpha\left(q_{t}-\alpha s_{t}\right)+f_{t}
$$

where $f_{t}$ is a shock to the current account balance that captures international financial flows other than those related to trade. ${ }^{1}$

The interest rate set by the monetary authority is assumed to follow

$$
i_{t}=\rho_{i} i_{t-1}+\left(1-\rho_{i}\right)\left(\psi_{\pi} \pi_{t}+\psi_{y} y_{t}+\psi_{\Delta y}\left(y_{t}-y_{t-1}\right)+\psi_{e}\left(q_{t}-q_{t-1}-\pi_{t}^{*}+\pi_{t}\right)\right)+m_{t}
$$

where $\varepsilon_{m, t}$ is a monetary policy shock, $\rho_{i}$ is the degree of interest rate smoothing while $\psi_{\pi}$, $\psi_{y}, \psi_{\Delta y}$ and $\psi_{e}$ describe how the policy rate reacts to, respectively, inflation, output, output growth and change in the nominal exchange rate.

The shock processes are modelled as simple first-order autoregressions $\left(z_{t}, g_{t}, c p_{t}, \phi_{t}\right.$ and $f_{t}$ ), white noise $\left(m_{t}\right)$, or are jointly determined within a vector autoregression with two lags $\left(\pi_{t}^{*}, y_{t}^{*}\right.$ and $\left.i_{t}^{*}\right)$.

\subsection{Model variants}

The full NOEM model described above, which we dub JP+ as it is a (minor) extension of the original Justiniano and Preston (2010b) setup, features nine exogenous shocks. We estimate it using nine observable variables: domestic output $y_{t}$, inflation $\pi_{t}$, and the interest rate $i_{t}$, foreign counterparts of these variables $y_{t}^{*}, \pi_{t}^{*}$ and $i_{t}^{*}$, as well as the real exchange rate $q_{t}$, terms of trade $s_{t}$, and current account balance $c a_{t}$.

Additionally, we consider the following three variants, each of which is nested in JP+. The first one leaves out the current account shock $f_{t}$ so that the model is identical to one developed by Justiniano and Preston (2010b), and hence we call it JP. To keep the number of observables not greater than the number of shocks, we exclude the terms of trade from the set of observed variables. To understand the reasons for choosing this variable as the one to be dropped, let us combine equations (10) and (3) to obtain

$$
s_{t}=\frac{\frac{1-\alpha}{\alpha} c a_{t}+y_{t}-y_{t}^{*}+(1-\alpha-\eta) q_{t}}{\eta+\alpha(1-\alpha)} .
$$

Note that if foreign output and the real exchange rate is included in estimation (as in JP), this equation does not include any shocks nor other non-observable variables, and so the

\footnotetext{
${ }^{1}$ The presence of this shock is our only extension to the Justiniano and Preston (2010b) model. It allows us to use the current account balance as an additional observable variable in estimation in the richest model variant.
} 
terms of trade can be uniquely identified. Naturally, the thus obtained series of this variable may be very different from what is actually observed. If, as some of the earlier literature suggests (see e.g. Lubik and Schorfheide, 2007 or Justiniano and Preston, 2010a), the model is misspecified in terms of its ability to match the comovement of the terms of trade with other variables, including the domestic ones that this paper is focused on, treating it as unobservable in estimation may actually help in forecasting.

The third NOME variant very closely resembles the setup used by Lubik and Schorfheide (2007) and hence we denote it as LS. Compared with JP, this version is obtained by additionally dropping shocks to preferences $g_{t}$, import markups $c p_{t}$ and risk premium $\phi_{t}$. Its main feature is that it treats the three foreign variables $y_{t}^{*}, \pi_{t}^{*}$ and $i_{t}^{*}$ as unobservable.

Our fourth and final version is the standard closed economy New Keynesian model, which is obtained by setting the country openness parameter $\alpha$ to zero so that $y_{t}=c_{t}, \pi_{t}=\pi_{H, t}$ and the dynamics of domestic variables $y_{t}, \pi_{t}$ and $i_{t}$, which are also the only ones used in estimation, can be described by the following system of three equations

$$
\begin{gathered}
y_{t}=\frac{1}{1+h} \mathbb{E}_{t} y_{t+1}+\frac{h}{1+h} y_{t-1}-\frac{1-h}{\sigma(1+h)}\left(i_{t}-\mathbb{E}_{t} \pi_{t+1}-g_{t}+\mathbb{E}_{t} g_{t+1}\right) \\
\pi_{t}=\frac{\beta}{1+\beta \delta_{H}} \mathbb{E}_{t} \pi_{t+1}+\frac{\delta_{H}}{1+\beta \delta_{H}} \pi_{t-1}+\frac{\left(1-\theta_{H}\right)\left(1-\beta \theta_{H}\right)}{\theta_{H}\left(1+\beta \delta_{H}\right)} m c_{t} \\
i_{t}=\rho_{i} i_{t-1}+\psi_{\pi} \pi_{t}+\psi_{y} y_{t}+\psi_{\Delta y}\left(y_{t}-y_{t-1}\right)+m_{t}
\end{gathered}
$$

where marginal cost is

$$
m c_{t}=\varphi y_{t}-(1+\varphi) z_{t}+\frac{\sigma}{1-h}\left(y_{t}-h y_{t-1}\right)
$$

\section{How does external sector affect domestic variables?}

In the NK model, fluctuations in output, inflation and the interest rate depend only on the following three domestic disturbances, broadly interpretable as affecting supply $\left(z_{t}\right)$, demand $\left(g_{t}\right)$ and monetary policy $\left(m_{t}\right)$. In the NOEM variants LS, JP and JP + , these three domestic variables are additionally affected by (all or a subset of) the following shocks specific to the external sector: $c p_{t}, \phi_{t}, f_{t}, \pi_{t}^{*}, y_{t}^{*}$ and $i_{t}^{*}$. This impact can be both direct or indirect through the impact on other endogenous variables such as the real exchange rate, terms of trade and the current account balance. Naturally, the inclusion of the external sector in the model also affects the transmission of standard domestic shocks. In this sense, if the model is correctly specified and estimation error is not large, inclusion of variables related to the external block in estimation should help better describe the evolution of, and generate more 
accurate forecasts for, domestic variables.

Before we move to our empirical investigation, it is instructive to look at how each of the variables included in the NOEM models, but not in the NK setup, i.e. $q_{t}, s_{t}, c a_{t}, y_{t}^{*}, \pi_{t}^{*}$ and $i_{t}^{*}$, may contribute to explaining the evolution of domestic output, inflation and the interest rate. To this end, let us first consider the model with the richest structure, i.e. the JP+. By substituting $c_{t}$ in equation (1) from the market clearing condition (3) we obtain

$y_{t}=\frac{1}{1+h} \mathbb{E}_{t} y_{t+1}+\frac{h}{1+h} y_{t-1}+\alpha x_{t}-\frac{\alpha}{1+h} \mathbb{E}_{t} x_{t+1}-\frac{h \alpha}{1+h} x_{t-1}-\frac{(1-h)(1-\alpha)}{\sigma(1+h)}\left(i_{t}-\mathbb{E}_{t} \pi_{t+1}+\mathbb{E}_{t} \Delta g_{t+1}\right)$

where $x_{t}=\eta\left(q_{t}+s_{t}\right)+y_{t}^{*}$. Hence, if $\alpha>0$, domestic output depends not only on the real interest rate and preference shocks, but also on current, past and expected future movements in the real exchange rate, terms of trade and foreign output.

Turning to inflation, let us assume for the ease of exposition that the degree of indexation for domestically produced and imported goods is the same, i.e. $\delta_{H}=\delta_{F}=\delta$. Then the Phillips curves (5) and (6) together with the definition of CPI (2) imply

$$
\pi_{t}=\frac{\beta}{1+\beta \delta} \mathbb{E}_{t} \pi_{t+1}+\frac{\delta}{1+\beta \delta} \pi_{t-1}+(1-\alpha) \kappa_{H} m c_{t}+\alpha \kappa_{F}\left(q_{t}-(1-\alpha) s_{t}\right)+\alpha c p_{t},
$$

where $\kappa_{i}=\frac{\left(1-\theta_{i}\right)\left(1-\beta \theta_{i}\right)}{\theta_{i}(1+\beta \delta)}$ for $i=\{H, F\}$. The above equation clearly indicates that the real exchange rate and terms of trade have an effect on inflation. Moreover, observing these variables and foreign output also allows to pin down the level of consumption in equation (3), and hence the marginal cost using equation (7).

Finally, since the interest rate is determined by the feedback rule (11) that depends on output and inflation, external sector variables listed above also affect the evolution of this variable. Moreover, as the rule also includes change in the nominal exchange rate, it is also affected by foreign inflation.

Even though the direct impact of $c a_{t}$ and $i^{*}$ in equations (17) and (17) is null, the link between domestic variables and these two external sector variables occurs indirectly through their impact on the real exchange rate as implied by the UIP condition (8). More specifically, the foreign interest rate enters directly the UIP equation while the current account balance affects the risk premium related to accumulation of net foreign assets.

\section{Data and estimation}

Our empirical investigation is based on quarterly data for Australia, Canada and the United Kingdom. The database covers the period from 1975:1 to 2013:4, of which 1995:1 marks 
the beginning of the forecast evaluation sample. For each of the investigated countries, the foreign sector is represented by the US, euro area, Japan and the remaining two analyzed economies. The weights are based on the BIS effective exchange rate (EER) indices over the period 1993-2010. All data sources and detailed weights, as well as the measurement equations linking the DSGE model variables to observed time series are presented in the Appendix.

To evaluate the forecasting performance of our model variants, we estimate them separately for all three countries using recursive samples, and then generate the out-of-sample forecasts. As in Justiniano and Preston (2010b), we calibrate the following three parameters before estimation: the discount factor $\beta$, risk premium elasticity $\chi$, and openness $\alpha$. All remaining structural parameters are estimated using Bayesian methods as described e.g. by An and Schorfheide (2007), with prior assumptions identical to those used by Justiniano and Preston (2010b). For the long run trends, which are captured by constants in the measurement equations, we assume uniform prior distributions. This is done to avoid criticism by Faust and Wright (2013), who argue that the good ex-post performance of DSGE models found in the earlier studies can be attributed to tight priors imposed on the steady-state values of the observed time series, especially in the context of forecasting inflation. The calibrated parameter values and prior assumptions are discussed in the Appendix.

The posterior distribution of parameters is approximated with 200,000 draws obtained with the Metropolis-Hastings (MH) algorithm, after discarding the initial 50,000 draws. This number of draws was sufficient to achieve convergence according to standard diagnostics. Next, for every 20th parameter draw from the $\mathrm{MH}$ chain we generate three random draws of structural shocks over the forecasting horizon. Consequently, we have in total 30,000 draws from the predictive density that can be used to calculate both point (mean of draws) and density forecasts (log predictive scores). Since our evaluation sample covers 76 quarters from the period of 1995:1-2013:4, the $H$-quarter-ahead forecasts are examined on the basis of $76-(H-1)$ observations. It is worth emphasizing that since we have 76 different estimation windows, four models and three countries, we had to estimate DSGE models, check their convergence and draw from the predictive denisity 912 times.

\section{Results}

\subsection{Forecasting performance of DSGE models}

In order to assess if the inclusion of the foreign sector improves the precision of DSGE modelbased forecasts for domestic variables, we start by comparing the root mean squared forecast 
errors (RMSFE) calculated with four model variants for the three considered economies, i.e. Australia, Canada and the United Kingdom. The results for output, the price level and the interest rate are shown in Table 1. All figures are presented as ratios of the RMSFE for a given model relative to the RMSFE for the NK benchmark so that values below unity show that a given NOEM model outperforms the closed economy setup. Moreover, we test whether the values are significantly different from unity with the two-tailed Diebold-Mariano test.

A number of observations are immediately evident. First, the richest NOEM variant JP+ generates forecasts for output, inflation and the interest rate that are at best indistinguishable from, and in most cases significantly less accurate than in the NK benchmark. The only exception is the 12-quarters-ahead forecast for output in Canada. Second, the JP variant that treats the terms of trade as unobservable fares on average a litlle better, but offers significant improvement over the NK benchmark only for the UK interest rates in the shortrun horizon. Third, the most parsimonious NOEM specification, i.e. LS setup, helps better predict output in Canada and Australia at longer horizons, but usually delivers large forecast errors for nominal domestic variables. A general picture is that none of the analyzed NOEM models can consistently beat the NK benchmark for any of the countries included in our sample. Whenever the differences between the RMSFEs are statistically significant, they usually point at the closed economy model as the preferred forecasting tool.

The picture is similar when we compare the quality of density forecasts using the log predictive scores (LPS), which are calculated with the method proposed by Adolfson et al. (2007b). Table 2 presents the average LPS differences of a given model in comparison to the NK benchmark so that positive values indicate that a given NOEM model outperforms the closed economy setup. We test whether the values are significantly different from zero with the two-tailed Amisano and Giacomini (2007) test. The results indicate that none of the three NOEM models can consistently beat the NK benchmark, and in many cases the quality of density forecasts they generate is significantly worse. As regards the multivariate density forecasts for the three domestic variables, the LPSs obtained from the NOEM models are either indistinguishable from or significantly lower than in the closed economy benchmark, with only one exception: 12-quarter horizon for Canada in the JP+ varuabt. The case of Australia is particularly telling as, for all horizons and NOEM variants, the quality of multi-variate density forecasts is significantly below those obtained from the closed economy setup.

There are three possible explanations for the disappointing forecasting performance of NOEM models documented in the previous section. The first one is that the NOEM framework, and especially those of its ingredients that make up an open economy extension of the standard closed economy NK setup, are severely misspecified. The second explanation 
is related to the model size: since the structure of the NOEM models is richer than that of the NK benchmark, it is more prone to estimation error, which can have a detrimental effect on the open economy models' out-of-sample performance. Third, the prior in NOEM models may be centered on wrong values. To examine which of the above three factors is most important, we conduct two additional analyses. First, we perform an analogous forecasting competition using Bayesian VARs. Second, we run a Monte Carlo experiment, in which we assume that $\mathrm{JP}+$ is the true data generating process (DGP).

\subsection{Evidence from BVARs}

The first analysis is to compare the forecasting performance of four BVAR models that are estimated on the same set of data as the DSGE models. For that reason we dub them exactly the same as their twin DSGE models (NK, LS, JP and JP+). We apply the standard NormalWishart prior, as proposed by Kadiyala and Karlsson (1997), that is centered around the random walk with precision dependent on the following hyperparameters: overall tightness set to 0.2 and decay fixed at 1 .

It turns out that the Bayesian VAR that includes only the three domestic variables (NK) cannot be consistently beaten by any of the three open economy extensions, see Tables 3 and 4. This result, which is in opposition to the Large Bayesian VAR literature (Banbura et al., 2010), becomes more intuitive if we notice that we do not change the overall tighness hyperparameter when increasing the model size, as it usually done in the Large Bayesian VAR studies. In this context it worth referring to the recent study by Gurkaynak et al. (2013), in which the authors argue that small-scale VARs usually generate better forecasts than large-scale VARs because of the larger estimation error in the latter. To conlude, the Bayesian VAR forecasting competition shows that the advantage of using additional data for the external block is not enough to compensate for increased estimation forecast error related to the fact that in open economy VAR models a larger number of parameters has to be estimated.

\subsection{Monte Carlo experiment}

Our second analysis uses a Monte Carlo experiment inspired by Herbst and Schorfheide (2012). The aim is to check whether the JP+ open economy model variant can outperform the NK benchmark even if the data are generated by the former. More precisely, we generate an artificial sample of data from the JP+ model with fixed structural parameters, using a random sequence of shocks. We next estimate the JP+ and NK models recursively on this artificial data set, generate forecasts and calculate the RMFSE statistics. The size of the sample as 
well as its split between estimation and evaluation subsamples is identical to that applied while we were working with actual data for Australia, Canada and the United Kingdom. We repeat this procedure 27 times, which gives us a distribution of relative RMFSEs from the two models, conditional on the data generating process coming from the JP+ variant. Note that, given the size of our evaluation sample, for every artificial data series we had to estimation DSGE models 152 times.

While generating the artificial data series, we fix the JP+ structural parameters as follows. The openness parameter $\alpha$ is set to 0.18 , which is the value we used before for Canada. As regards other parameters, we use the insights from the prior-posterior comparisons documented by Justiniano and Preston (2010a). The VAR parameters are set to their posterior means from the full-sample estimates of the JP+ model for Canada so that the evolution of foreign variables in our artificial samples mimics those observed for this country's trade partners. As a general rule, other parameters are fixed at the calibrated values or prior means used to estimate the $\mathrm{JP}+$ models in the forecasting evaluation exercise described in Section 5.1. We deviate from this principle only in the case of standard deviations of structural shocks, motivating our choices by the desire to make the properties of the artificial time series resemble actual data as much as possible. This is a necessary step as the prior assumptions for shock volatility used by Justiniano and Preston (2010b) are not motivated empirically and in particular imply aggregate fluctuations that are much smaller than those observed in the data. More specifically, we set the standard deviation of innovations to $1 \%$ for productivity and preference shocks, $0.5 \%$ for monetary and risk premium shocks, $3 \%$ for import markup shocks and $1.5 \%$ for current account shocks. These numbers are chosen so that the artificial time series have roughly the same volatility as actual Canadian data, see Table 6.

Note that, by following the rules described above, and in particular by fixing the non-VAR parameters at their prior rather than posterior means, shocks related to the foreign sector are important drivers of the artificial data that we use in the Monte Carlo experiment, see Table 6 . In this respect, these artificial time series are in line with empirical findings on the importance of international linkages for small open economies, which can be contrasted with the implications of estimated NOEM models (Justiniano and Preston, 2010a). This, together with the fact that while estimating the JP+ model on artificially generated data we use prior distributions that are centered around the exact values that were used to parametrize the data generating process, should give substantial specification advantage to the $\mathrm{JP}+$ variant over the NK competitor. In consequence, the only important reason why the latter could win the forecasting competition is a more parsimonious structure, i.e. lower estimation error.

The results of our Monte Carlo experiment are collected in Table 7. At first glance, the results seem to confirm the superior performance of the JP+ model over its NK rival as 
in most cases it is the former that generates forecasts with lower RMSFEs for all horizons. However, the gains turn out to be small, with the median gain averaged over forecast horizons equal to $5 \%$ for output and only $2 \%$ for the price level and interest rate. More imporatantly, if we were to apply the Diebold-Mariano test to judge whether the gains in forecast quality are statistically significant, we would give a positive verdict only in $23 \%$ cases for output, $10 \%$ for prices and $14 \%$ for the interest rates.

Overall, these results clearly show that an increase in the forecast esimation error due to extending the standard NK setup to an open economy is large enough to roughly offset the potential gains arising from a better specification and correct priors in the JP + framework. If one additionally takes into account that, as some of the earlier literature suggests, the NOEM framework might be misspecified, and additionally the priors may be badly chosen, it is no longer surprising that for the three analyzed economies, Australia, Canada and the United Kingdom, we have found that NOEM forecasts are significantly less accurate than those obtained from a closed economy framework.

\section{Conclusions}

In this paper we have shown that adding a foreign sector block to estimated DSGE models for Australia, Canada and the United Kingdom does not necessarily result in a significant improvement in the forecast accuracy for domestic variables, and in many cases makes them even less precise. According to our Monte Carlo experiment, this result can be at least partially explained by an increase in estimation error that roughly offsets the gains related to potentially better specification.

It is important to note that in our forecasting race we used data for three open economies, for which the available time series can be considered rather long. Similarly, our Monte Carlo experiment was based on simulated data of the same length as for these three countries. This means that, if one applies the NOEM framework to other countries, and emerging economies in particular, the role of estimation error is very likely to be even larger, with negative consequences for forecast quality.

Naturally, DSGE models are not used just to generate forecasts and their numerous alternative applications may make the presence of the foreign block highly desired, if not indispensable. However, we believe that awareness of possible consequences of including open economy variables for forecast quality is important. 


\section{References}

Adolfson, M., Laseen, S., Linde, J., Villani, M., 2007a. Bayesian estimation of an open economy DSGE model with incomplete pass-through. Journal of International Economics $72(2), 481-511$.

Adolfson, M., Laseen, S., Linde, J., Villani, M., 2008. Evaluating an estimated new Keynesian small open economy model. Journal of Economic Dynamics and Control 32 (8), 2690-2721.

Adolfson, M., Linde, J., Villani, M., 2007b. Forecasting performance of an open economy DSGE model. Econometric Reviews 26 (2-4), 289-328.

Alpanda, S., Kotze, K., Woglom, G., 2011. Forecasting performance of an estimated DSGE Model for the South African economy. South African Journal of Economics 79 (1), 50-67.

Amisano, G., Giacomini, R., 2007. Comparing density forecasts via weighted likelihood ratio tests. Journal of Business \& Economic Statistics 25, 177-190.

An, S., Schorfheide, F., 2007. Bayesian analysis of DSGE models. Econometric Reviews $26(2-4), 113-172$.

Banbura, M., Giannone, D., Reichlin, L., 2010. Large Bayesian vector auto regressions. Journal of Applied Econometrics 25 (1), 71-92.

Bergin, P. R., 2003. Putting the 'New Open Economy Macroeconomics' to a test. Journal of International Economics 60 (1), 3-34.

Bergin, P. R., 2006. How well can the New Open Economy Macroeconomics explain the exchange rate and current account? Journal of International Money and Finance 25 (5), $675-701$.

Ca' Zorzi, M., Kolasa, M., Rubaszek, M., 2016. Exchange rate forecasting with DSGE models. Working Paper Series, forthcoming, European Central Bank.

Christiano, L. J., Eichenbaum, M., Evans, C. L., 2005. Nominal rigidities and the dynamic effects of a shock to monetary policy. Journal of Political Economy 113 (1), 1-45.

Christoffel, K., Coenen, G., Warne, A., 2010. Forecasting with DSGE models. Working Paper Series 1185, European Central Bank.

Del Negro, M., Schorfheide, F., 2012. DSGE model-based forecasting. In: Elliott, G., Timmermann, A. (Eds.), Handbook of Economic Forecasting. Vol. 2 of Handbook of Economic Forecasting. Elsevier. 
Devereux, M. B., Engel, C., 2003. Monetary Policy in the Open Economy Revisited: Price Setting and Exchange-Rate Flexibility. Review of Economic Studies 70 (4), 765-783.

Engel, C., 2014. Exchange rates and interest parity. In: Gita Gopinath, E. H., Rogoff, K. (Eds.), Handbook of International Economics. Vol. 4. Elsevier, Ch. 8, pp. 453-522.

Faust, J., Wright, J. H., 2013. Forecasting inflation. In: Elliott, G., Timmermann, A. (Eds.), Handbook of Economic Forecasting. Vol. 2. Elsevier, Ch. 1.

Gali, J., Monacelli, T., 2005. Monetary policy and exchange rate volatility in a small open economy. The Review of Economic Studies 72 (3), 707-734.

Gourinchas, P.-O., Rey, H., 2014. External adjustment, global imbalances, valuation effects. In: Gita Gopinath, E. H., Rogoff, K. (Eds.), Handbook of International Economics. Elsevier, pp. 585-645.

Gupta, R., Kabundi, A., 2010. Forecasting macroeconomic variables in a small open economy: A comparison between small- and large-scale models. Journal of Forecasting 29 (1-2), 168185.

Gurkaynak, R. S., Kisacikoglu, B., Rossi, B., 2013. Do DSGE models forecast more accurately out-of-sample than VAR models? CEPR Discussion Papers 9576, The Center for Economic and Policy Research.

Herbst, E., Schorfheide, F., 2012. Evaluating dsge model forecasts of comovements. Journal of Econometrics 171 (2), 152-166.

Justiniano, A., Preston, B., May 2010a. Can structural small open-economy models account for the influence of foreign disturbances? Journal of International Economics 81 (1), 61-74.

Justiniano, A., Preston, B., 2010b. Monetary policy and uncertainty in an empirical small open-economy model. Journal of Applied Econometrics 25 (1), 93-128.

Kadiyala, K. R., Karlsson, S., March-Apr 1997. Numerical Methods for Estimation and Inference in Bayesian VAR-Models. Journal of Applied Econometrics 12 (2), 99-132.

Klau, M., Fung, S. S., March 2006. The new BIS effective exchange rate indices. BIS Quarterly Review.

Lubik, T. A., Schorfheide, F., 2007. Do central banks respond to exchange rate movements? A structural investigation. Journal of Monetary Economics 54 (4), 1069-1087. 
Marcellino, M., Rychalovska, Y., 08 2014. Forecasting with a DSGE Model of a Small Open Economy within the Monetary Union. Journal of Forecasting 33 (5), 315-338.

Matheson, T., 2010. Assessing the fit of small open economy DSGEs. Journal of Macroeconomics 32 (3), 906-920.

Obstfeld, M., Rogoff, K., 1995. Exchange Rate Dynamics Redux. Journal of Political Economy 103 (3), 624-60.

Smets, F., Wouters, R., 2007. Shocks and frictions in US business cycles: A Bayesian DSGE approach. American Economic Review 97 (3), 586-606. 


\section{Tables and figures}

Table 1: Root Mean Squared Forecast Error (RMSFE) for DSGE models

\begin{tabular}{|l|lll|llll|lll|}
\hline Horizon & \multicolumn{3}{|c|}{ United Kingdom } & \multicolumn{3}{c|}{ Canada } & \multicolumn{3}{c|}{ Australia } \\
\hline & LS & JP & JP + & LS & JP & JP + & LS & JP & JP + \\
\hline & \multicolumn{7}{|c|}{ Output } \\
\hline 1 & $1.27^{*}$ & $1.11^{* * *}$ & $1.13^{* * *}$ & $1.43^{* *}$ & $1.21^{*}$ & $1.08^{* *}$ & 1.03 & $1.07^{* * *}$ & $1.17^{* * *}$ \\
4 & $1.23^{*}$ & $1.12^{* * *}$ & $1.15^{* * *}$ & $1.24^{* *}$ & 1.13 & 1.02 & 1.03 & $1.07^{* *}$ & $1.24^{* * *}$ \\
6 & $1.16^{* *}$ & $1.08^{* * *}$ & $1.14^{* * *}$ & 1.12 & $1.13^{* *}$ & 0.97 & 0.97 & $1.08^{* * *}$ & $1.25^{* * *}$ \\
8 & $1.14^{* *}$ & $1.07^{* * *}$ & $1.13^{* * *}$ & 1.03 & $1.13^{* * *}$ & 0.95 & 0.89 & $1.09^{* * *}$ & $1.19^{* * *}$ \\
12 & $1.13^{* *}$ & $1.07^{* * *}$ & $1.12^{* * *}$ & 0.99 & $1.12^{* * *}$ & 0.94 & $0.82^{* *}$ & $1.08^{* * *}$ & $1.10^{* * *}$ \\
\hline & 1.11 & $1.07^{* * *}$ & $1.09^{* * *}$ & 0.91 & $1.10^{* * *}$ & $0.92^{* *}$ & $0.72^{* * *}$ & $1.08^{* * *}$ & 0.98 \\
\hline 1 & \multicolumn{8}{|c|}{ Prices } \\
2 & $1.19^{* *}$ & 1.06 & $1.12^{* * *}$ & $1.21^{*}$ & 0.91 & $1.06^{*}$ & 1.04 & 1.03 & $1.07^{*}$ \\
4 & $1.28^{* *}$ & 1.00 & $1.20^{* * *}$ & $1.32^{*}$ & 0.89 & $1.13^{* *}$ & 1.06 & 1.05 & $1.09^{*}$ \\
6 & $1.33^{* *}$ & 0.93 & $1.30^{* * *}$ & $1.56^{* *}$ & 0.89 & $1.26^{* *}$ & 1.05 & 1.06 & 1.11 \\
8 & $1.34^{* *}$ & 0.90 & $1.36^{* * *}$ & $1.82^{* *}$ & 0.94 & $1.41^{* * *}$ & 1.03 & 1.08 & 1.09 \\
12 & $1.30^{* *}$ & 0.89 & $1.37^{* * *}$ & $1.94^{* *}$ & 0.98 & $1.54^{* * *}$ & 1.01 & 1.09 & 1.04 \\
\hline \multicolumn{8}{|c|}{ Interest rates } & $1.11^{*}$ & 0.98 \\
\hline 1 & $1.22^{* *}$ & 0.90 & $1.40^{* * *}$ & $2.22^{* *}$ & 1.06 & $1.82^{* * *}$ & 1.05 & & & \\
2 & $1.33^{*}$ & $0.86^{* *}$ & 0.91 & 1.13 & 0.99 & 0.98 & 1.01 & 1.04 & 1.15 \\
4 & $1.30^{*}$ & $0.85^{* * *}$ & 0.95 & 1.16 & 0.95 & 1.05 & 0.94 & $1.09^{*}$ & 1.17 \\
6 & $1.28^{* *}$ & $0.89^{* * *}$ & 1.06 & 1.21 & 0.96 & $1.16^{* * *}$ & 1.00 & $1.14^{* *}$ & $1.21^{* *}$ \\
8 & $1.28^{* *}$ & 0.95 & $1.20^{*}$ & 1.21 & 0.95 & $1.22^{* * *}$ & 1.09 & $1.18^{* * *}$ & $1.23^{* * *}$ \\
12 & $1.26^{* *}$ & 0.97 & $1.29^{* *}$ & 1.18 & 0.92 & $1.27^{* * *}$ & 1.20 & $1.22^{* * *}$ & $1.21^{* * *}$ \\
\hline & $1.25^{* * *}$ & 0.99 & $1.45^{* * *}$ & 1.15 & $0.86^{*}$ & $1.35^{* * *}$ & $1.37^{* *}$ & $1.26^{* * *}$ & $1.18^{* * *}$ \\
\hline
\end{tabular}

Notes: The figures in the table represent the ratios of the RMSFE from a given model in comparison to the NK benchmark so that the values below unity indicate that forecasts from a given NOEM variant are more accurate than from the benchmark. Asterisks ${ }^{* * *},{ }^{* *}$ and ${ }^{*}$ denote, respectively, the $1 \%, 5 \%$ and $10 \%$ significance levels of the two-tailed Diebold-Mariano test, where the long-run variance is calculated with the Newey-West method. 
Table 2: Log Predictive Scores (LPS) for DSGE models

\begin{tabular}{|c|c|c|c|c|c|c|c|c|c|}
\hline \multirow[t]{2}{*}{ Horizol } & \multicolumn{3}{|c|}{ United Kingdom } & \multicolumn{3}{|c|}{ Canada } & \multicolumn{3}{|c|}{ Australia } \\
\hline & LS & $\mathrm{JP}$ & $\mathrm{JP}+$ & $\mathrm{LS}$ & $\mathrm{JP}$ & $\mathrm{JP}+$ & LS & $\mathrm{JP}$ & $\mathrm{JP}+$ \\
\hline & \multicolumn{9}{|c|}{ Output } \\
\hline 1 & $-0.15^{* * *}$ & $-0.07^{* * *}$ & $-0.08^{* * *}$ & $-0.35^{* * *}$ & $-0.18^{*}$ & -0.06 & 0.00 & $-0.06^{* * *}$ & $-0.09^{* * *}$ \\
\hline 2 & $-0.14^{*}$ & -0.06 & $-0.08^{* * *}$ & $-0.25^{* *}$ & -0.10 & 0.00 & 0.01 & $-0.06^{* * *}$ & $-0.12^{* * *}$ \\
\hline 4 & -0.16 & -0.10 & $-0.12^{* * *}$ & -0.20 & $-0.11^{*}$ & 0.02 & 0.05 & $-0.06^{* * *}$ & $-0.19^{* * *}$ \\
\hline 6 & $-0.21^{*}$ & -0.17 & $-0.16^{* * *}$ & -0.17 & $-0.16^{*}$ & 0.02 & 0.09 & $-0.07^{* * *}$ & $-0.24^{* * *}$ \\
\hline 8 & $-0.26^{* *}$ & -0.24 & $-0.20^{* * *}$ & -0.21 & $-0.21^{* *}$ & 0.01 & $0.13^{* *}$ & $-0.08^{* * *}$ & $-0.28^{* *}$ \\
\hline \multirow[t]{2}{*}{12} & $-0.37^{* * *}$ & $-0.37^{* * *}$ & $-0.29^{* * *}$ & -0.13 & $-0.30^{* *}$ & -0.01 & $0.19^{* * *}$ & $-0.12^{* * *}$ & $-0.31^{* *}$ \\
\hline & \multicolumn{9}{|c|}{ Prices } \\
\hline 1 & $-0.13^{* * *}$ & $-0.24^{* * *}$ & $-0.03^{* * *}$ & -0.13 & -0.04 & $-0.07^{* *}$ & $-0.18^{* * *}$ & $-0.07^{* * *}$ & $-0.07^{* * *}$ \\
\hline 2 & $-0.07^{* * *}$ & $-0.05^{* * *}$ & $-0.01^{*}$ & -0.17 & 0.00 & $-0.10^{* * *}$ & $-0.16^{* * *}$ & $-0.05^{* * *}$ & $-0.09^{* * *}$ \\
\hline 4 & 0.00 & $0.14^{* * *}$ & -0.01 & $-0.21^{* *}$ & $0.08^{*}$ & $-0.13^{* * *}$ & $-0.15^{* * *}$ & $-0.04^{* *}$ & $-0.11^{* * *}$ \\
\hline 6 & 0.03 & $0.22^{* * *}$ & -0.02 & $-0.24^{* *}$ & $0.13^{* * *}$ & $-0.14^{* * *}$ & $-0.17^{* * *}$ & $-0.04^{* *}$ & $-0.11^{* * *}$ \\
\hline 8 & 0.04 & $0.26^{* * *}$ & -0.04 & $-0.23^{* *}$ & $0.16^{* * *}$ & $-0.15^{* * *}$ & $-0.19^{* * *}$ & $-0.05^{* *}$ & $-0.09^{* * *}$ \\
\hline \multirow[t]{2}{*}{12} & $0.07^{*}$ & $0.27^{* * *}$ & -0.09 & $-0.21^{* *}$ & $0.19^{* * *}$ & $-0.19^{* * *}$ & $-0.27^{* * *}$ & $-0.06^{* *}$ & $-0.08^{* *}$ \\
\hline & \multicolumn{9}{|c|}{ Interest rates } \\
\hline 1 & $-0.13^{* * *}$ & $-0.06^{* * *}$ & $-0.03^{* * *}$ & $-0.06^{*}$ & $-0.04^{* *}$ & -0.02 & $0.04^{* *}$ & $-0.04^{* * *}$ & $-0.03^{*}$ \\
\hline 2 & $-0.13^{* * *}$ & $-0.04^{* *}$ & -0.02 & -0.05 & -0.02 & -0.03 & $0.03^{* *}$ & $-0.05^{* * *}$ & -0.03 \\
\hline 4 & $-0.11^{*}$ & 0.01 & -0.02 & -0.04 & 0.02 & -0.05 & -0.02 & $-0.06^{* * *}$ & $-0.06^{* * *}$ \\
\hline 6 & -0.09 & 0.03 & -0.06 & -0.05 & $0.05^{* * *}$ & $-0.09^{* *}$ & $-0.09^{* * *}$ & $-0.07^{* * *}$ & $-0.07^{* * *}$ \\
\hline 8 & -0.06 & $0.04^{*}$ & $-0.09^{*}$ & -0.04 & $0.08^{* * *}$ & $-0.11^{* * *}$ & $-0.15^{* * *}$ & $-0.08^{* * *}$ & $-0.07^{* * *}$ \\
\hline \multirow[t]{2}{*}{12} & -0.03 & $0.05^{* *}$ & $-0.15^{* * *}$ & -0.02 & $0.13^{* * *}$ & $-0.14^{* * *}$ & $-0.26^{* * *}$ & $-0.10^{* * *}$ & $-0.06^{* *}$ \\
\hline & \multicolumn{9}{|c|}{ Three variables } \\
\hline 1 & $-0.44^{* * *}$ & $-0.31^{* * *}$ & $-0.11^{* * *}$ & $-0.59^{* * *}$ & $-0.31^{* *}$ & $-0.17^{* * *}$ & $-0.13^{* * *}$ & $-0.15^{* * *}$ & $-0.17^{* * *}$ \\
\hline 2 & $-0.41^{* *}$ & $-0.09^{* * *}$ & $-0.06^{* *}$ & $-0.66^{* * *}$ & $-0.23^{* *}$ & -0.11 & $-0.13^{* *}$ & $-0.12^{* * *}$ & $-0.24^{* * *}$ \\
\hline 4 & -0.43 & 0.02 & -0.04 & $-0.85^{* * *}$ & $-0.18^{* *}$ & 0.01 & $-0.16^{* *}$ & $-0.13^{* * *}$ & $-0.35^{* * *}$ \\
\hline 6 & -0.46 & -0.01 & -0.06 & $-0.90^{* * *}$ & $-0.18^{* *}$ & 0.10 & $-0.20^{* *}$ & $-0.15^{* * *}$ & $-0.43^{* * *}$ \\
\hline 8 & -0.47 & -0.05 & -0.08 & $-0.86^{* * *}$ & $-0.17^{* *}$ & 0.16 & $-0.24^{* * *}$ & $-0.16^{* * *}$ & $-0.47^{* * *}$ \\
\hline 12 & -0.49 & -0.16 & $-0.15^{*}$ & -0.50 & $-0.16^{*}$ & $0.23^{*}$ & $-0.36^{* * *}$ & $-0.21^{* * *}$ & $-0.50^{* * *}$ \\
\hline
\end{tabular}

Notes: The figures in the table represent the differences of the LPS from a given model in comparison to the NK benchmark so that positive values indicate that forecasts from a given NOEM variant are more accurate than from the benchmark. Asterisks ${ }^{* * *},{ }^{* *}$ and ${ }^{*}$ denote, respectively, the $1 \%, 5 \%$ and $10 \%$ significance levels of the two-tailed Amisano and Giacomini (2007) test, where the long-run variance is calculated with the Newey-West method. 
Table 3: Root Mean Squared Forecast Error for BVAR models

\begin{tabular}{|c|c|c|c|c|c|c|c|c|c|}
\hline Horizon & \multicolumn{3}{|c|}{ United Kingdom } & \multicolumn{3}{|c|}{ Canada } & \multicolumn{3}{|c|}{ Australia } \\
\hline & $\mathrm{LS}$ & JP & $\mathrm{JP}+$ & $\mathrm{LS}$ & JP & $\mathrm{JP}+$ & LS & JP & $\mathrm{JP}+$ \\
\hline & \multicolumn{9}{|c|}{ Output } \\
\hline 1 & 1.04 & 1.00 & 1.00 & 1.08 & 1.07 & 1.08 & $1.14^{* * *}$ & $1.13^{* * *}$ & $1.18^{* * *}$ \\
\hline 2 & 1.03 & 0.97 & 0.97 & 1.09 & 1.11 & $1.17^{*}$ & $1.27^{* * *}$ & $1.23^{* * *}$ & $1.27^{* * *}$ \\
\hline 4 & 1.05 & 0.95 & 0.96 & 1.05 & 1.14 & 1.23 & $1.39^{* * *}$ & $1.31^{* * *}$ & $1.40^{* * *}$ \\
\hline 6 & 1.08 & 0.96 & 0.96 & 0.96 & 1.11 & 1.13 & $1.48^{* * *}$ & $1.33^{* * *}$ & $1.50^{* * *}$ \\
\hline 8 & 1.11 & 1.00 & 0.98 & 0.92 & 1.08 & 1.07 & $1.51^{* * *}$ & $1.29^{* *}$ & $1.54^{* * *}$ \\
\hline \multirow[t]{2}{*}{12} & $1.19^{* *}$ & 1.15 & 1.10 & 0.91 & 1.02 & 1.00 & $1.46^{* * *}$ & 1.14 & $1.41^{* *}$ \\
\hline & \multicolumn{9}{|c|}{ Prices } \\
\hline 1 & 0.92 & $0.83^{* *}$ & $0.78^{* *}$ & $1.05^{*}$ & 1.03 & 1.06 & 1.02 & 0.99 & 1.11 \\
\hline 2 & 0.91 & $0.82^{* *}$ & $0.75^{* *}$ & $1.09^{*}$ & 1.07 & $1.12^{*}$ & 1.02 & 0.97 & 1.15 \\
\hline 4 & 0.91 & $0.81^{* *}$ & $0.70^{* *}$ & 1.15 & 1.14 & $1.20^{* *}$ & 0.99 & 0.94 & 1.08 \\
\hline 6 & 0.93 & $0.84^{* *}$ & $0.68^{* *}$ & 1.22 & 1.22 & $1.30^{* *}$ & 0.95 & 0.90 & 1.07 \\
\hline 8 & 0.96 & 0.91 & $0.72^{* *}$ & 1.30 & $1.32^{*}$ & $1.43^{* *}$ & 0.94 & 0.90 & 1.12 \\
\hline \multirow[t]{2}{*}{12} & 1.03 & 1.03 & $0.82^{*}$ & 1.46 & $1.50^{*}$ & $1.64^{*}$ & 1.00 & 0.99 & 1.29 \\
\hline & \multicolumn{9}{|c|}{ Interest rates } \\
\hline 1 & $1.14^{*}$ & 1.06 & 1.07 & 1.13 & 1.01 & 1.05 & 1.00 & 0.99 & 1.12 \\
\hline 2 & 1.15 & 1.12 & 1.11 & 1.18 & 1.01 & 1.10 & 1.05 & 1.05 & 1.21 \\
\hline 4 & 1.14 & 1.20 & 1.08 & 1.25 & 1.06 & 1.20 & 1.15 & 1.15 & 1.24 \\
\hline 6 & 1.22 & $1.33^{*}$ & 1.15 & 1.28 & 1.15 & 1.29 & 1.22 & 1.25 & 1.29 \\
\hline 8 & 1.27 & $1.42^{*}$ & 1.19 & 1.28 & 1.20 & 1.34 & $1.27^{*}$ & $1.34^{*}$ & $1.48^{* * *}$ \\
\hline 12 & $1.30^{*}$ & $1.47^{* *}$ & $1.20^{*}$ & 1.17 & 1.17 & 1.30 & $1.41^{* *}$ & $1.59^{* * *}$ & $1.92^{* * *}$ \\
\hline
\end{tabular}

Notes: The figures in the table represent the ratios of the RMSFE from a given model in comparison to the NK (3-variable) benchmark so that the values below unity indicate that forecasts from a given open economy BVAR variant are more accurate than from the benchmark. Asterisks ${ }^{* * *},{ }^{* *}$ and ${ }^{*}$ denote, respectively, the $1 \%, 5 \%$ and $10 \%$ significance levels of the two-tailed Diebold-Mariano test, where the long-run variance is calculated with the Newey-West method. 
Table 4: Log Predictive Scores for BVAR models

\begin{tabular}{|c|c|c|c|c|c|c|c|c|c|}
\hline \multicolumn{4}{|c|}{ United Kingdom } & \multicolumn{3}{|c|}{ Canada } & \multicolumn{3}{|c|}{ Australia } \\
\hline & $\mathrm{LS}$ & $\mathrm{JP}$ & $\mathrm{JP}+$ & $\mathrm{LS}$ & $\mathrm{JP}$ & $\mathrm{JP}+$ & LS & $\mathrm{JP}$ & $\mathrm{JP}+$ \\
\hline & \multicolumn{9}{|c|}{ Output } \\
\hline 1 & -0.02 & 0.02 & 0.02 & -0.03 & -0.02 & -0.02 & $-0.06^{* * *}$ & $-0.05^{* * *}$ & $-0.09^{* * *}$ \\
\hline 2 & -0.01 & 0.06 & 0.05 & -0.07 & -0.08 & -0.13 & $-0.12^{* * *}$ & $-0.10^{* * *}$ & $-0.14^{* * *}$ \\
\hline 4 & -0.01 & 0.12 & 0.11 & -0.06 & -0.16 & -0.25 & $-0.19^{* * *}$ & $-0.16^{* * *}$ & $-0.21^{* * *}$ \\
\hline 6 & -0.06 & 0.13 & 0.12 & 0.03 & -0.15 & -0.17 & $-0.24^{* * *}$ & $-0.19^{* * *}$ & $-0.26^{* * *}$ \\
\hline 8 & -0.09 & 0.10 & 0.11 & 0.07 & -0.12 & -0.12 & $-0.28^{* * *}$ & $-0.19^{* * *}$ & $-0.29^{* * *}$ \\
\hline \multirow[t]{2}{*}{12} & $-0.16^{* *}$ & -0.04 & 0.00 & 0.13 & 0.02 & 0.02 & $-0.26^{* * *}$ & $-0.13^{* *}$ & $-0.26^{* * *}$ \\
\hline & \multicolumn{9}{|c|}{ Prices } \\
\hline 1 & 0.03 & $0.08^{* * *}$ & $0.12^{* * *}$ & $-0.04^{*}$ & -0.02 & -0.04 & -0.03 & -0.02 & $-0.08^{*}$ \\
\hline 2 & 0.05 & $0.10^{*}$ & $0.15^{* *}$ & $-0.07^{*}$ & -0.06 & $-0.10^{*}$ & -0.04 & -0.02 & $-0.12^{*}$ \\
\hline 4 & 0.10 & 0.15 & $0.26^{*}$ & -0.11 & -0.10 & $-0.15^{* *}$ & -0.04 & -0.02 & -0.11 \\
\hline 6 & 0.14 & 0.18 & $0.33^{*}$ & -0.14 & -0.13 & $-0.19^{* *}$ & -0.04 & -0.02 & -0.13 \\
\hline 8 & 0.13 & 0.16 & $0.32^{*}$ & -0.19 & $-0.18^{*}$ & $-0.25^{* *}$ & -0.06 & -0.06 & $-0.18^{*}$ \\
\hline \multirow[t]{2}{*}{12} & 0.07 & 0.04 & 0.19 & $-0.29^{* *}$ & $-0.29^{* * *}$ & $-0.36^{* * *}$ & -0.11 & $-0.15^{* *}$ & $-0.32^{* * *}$ \\
\hline & \multicolumn{9}{|c|}{ Interest rates } \\
\hline 1 & -0.01 & $0.02^{*}$ & $0.03^{* *}$ & -0.03 & $0.16^{* * *}$ & $0.14^{* * *}$ & 0.01 & $0.03^{*}$ & 0.01 \\
\hline 2 & -0.02 & 0.01 & 0.03 & $-0.06^{*}$ & $0.13^{* * *}$ & 0.08 & -0.01 & 0.03 & -0.01 \\
\hline 4 & -0.03 & -0.01 & 0.03 & $-0.13^{*}$ & 0.06 & -0.04 & $-0.06^{*}$ & -0.03 & -0.04 \\
\hline 6 & -0.05 & -0.06 & -0.02 & $-0.18^{* *}$ & -0.05 & -0.16 & $-0.11^{* * *}$ & $-0.09^{* *}$ & $-0.09^{* *}$ \\
\hline 8 & $-0.07^{*}$ & $-0.09^{*}$ & -0.05 & $-0.21^{* *}$ & -0.12 & -0.22 & $-0.14^{* * *}$ & $-0.14^{* * *}$ & $-0.18^{* * *}$ \\
\hline \multirow[t]{2}{*}{12} & $-0.10^{* * *}$ & $-0.14^{* * *}$ & $-0.12^{* * *}$ & $-0.20^{* * *}$ & $-0.13^{*}$ & $-0.21^{* *}$ & $-0.14^{* * *}$ & $-0.19^{* * *}$ & $-0.31^{* * *}$ \\
\hline & \multicolumn{9}{|c|}{ Three variables } \\
\hline 1 & 0.00 & $0.11^{* *}$ & $0.14^{* *}$ & -0.10 & 0.09 & 0.05 & $-0.08^{* *}$ & -0.04 & $-0.16^{* *}$ \\
\hline 2 & 0.02 & 0.15 & $0.20^{*}$ & -0.19 & -0.03 & -0.17 & $-0.16^{* * *}$ & $-0.11^{*}$ & $-0.28^{* *}$ \\
\hline 4 & 0.12 & 0.31 & $0.43^{*}$ & -0.29 & -0.19 & $-0.40^{*}$ & $-0.30^{* * *}$ & $-0.23^{* *}$ & $-0.40^{* * *}$ \\
\hline 6 & 0.18 & $0.50^{*}$ & $0.63^{* *}$ & -0.27 & -0.27 & -0.44 & $-0.41^{* * *}$ & $-0.34^{* * *}$ & $-0.53^{* * *}$ \\
\hline 8 & 0.21 & $0.61^{* *}$ & $0.72^{* *}$ & -0.28 & -0.34 & $-0.46^{*}$ & $-0.48^{* * *}$ & $-0.42^{* * *}$ & $-0.68^{* * *}$ \\
\hline 12 & 0.10 & 0.46 & $0.55^{*}$ & -0.24 & -0.32 & $-0.43^{*}$ & $-0.51^{* * *}$ & $-0.50^{* * *}$ & $-0.91^{* * *}$ \\
\hline
\end{tabular}

Notes: The figures in the table represent the differences of the LPS from a given model in comparison to the NK (3 variable) benchmark so that positive values indicate that forecasts from a given open economy BVAR variant are more accurate than from the benchmark. Asterisks ${ }^{* * *},{ }^{* *}$ and ${ }^{*}$ denote, respectively, the $1 \%, 5 \%$ and $10 \%$ significance levels of the two-tailed Amisano and Giacomini (2007) test, where the long-run variance is calculated with the Newey-West method. 
Table 5: Volatility of artificial data

\begin{tabular}{|l|cc|}
\hline Variables & Artificial data & Canadian data \\
\hline Output & 0.71 & 0.74 \\
Inflation & 0.90 & 0.84 \\
Interest rate & 3.75 & 3.98 \\
Terms of trade & 2.27 & 1.98 \\
Real exch. rate & 2.07 & 2.48 \\
Current account & 2.30 & 2.27 \\
Foreign output & 0.69 & 0.70 \\
Foreign inflation & 0.70 & 0.75 \\
Foreign int. rate & 2.70 & 3.52 \\
\hline
\end{tabular}

Notes: This table compares the unconditional standard deviations of artificial data generated from the JP+ model and used in the Monte Carlo experiment described in section 6 to actual Canadian data. All variables are defined in the same way as when they are used in estimation, see the left-hand sides of the measurement equations reported in the Appendix.

Table 6: Share of foreign block shocks in unconditional variance decomposition

\begin{tabular}{|l|cccc|}
\hline Variables & Artificial data & Australia & Canada & United Kingdom \\
\hline Output & 0.25 & 0.02 & 0.06 & 0.03 \\
Inflation & 0.29 & 0.07 & 0.22 & 0.12 \\
Interest rate & 0.54 & 0.19 & 0.34 & 0.26 \\
\hline
\end{tabular}

Notes: This table shows the share of foreign block shocks (i.e. affecting import markups, risk premium, current account, and three foreign variables), in the unconditional variance decomposition for domestic variables in our artificial data used in the Monte Carlo experiment described in section 6, and implied by the full-sample estimates of the JP+ model for Australia, Canada and the UK, with the numbers evaluated at the posterior mean of the estimated parameters. All variables are defined in the same way as when they are used in estimation, see the left-hand sides of the measurement equations reported in the Appendix. 
Table 7: Relative RMSFE of JP+ versus NK - Monte Carlo experiment

\begin{tabular}{|l|cccccc|}
\hline & $\mathrm{H}=1$ & $\mathrm{H}=2$ & $\mathrm{H}=4$ & $\mathrm{H}=6$ & $\mathrm{H}=8$ & $\mathrm{H}=12$ \\
\hline & \multicolumn{5}{|c|}{ Output } \\
\hline Median value & 0.94 & 0.97 & 0.96 & 0.96 & 0.93 & 0.95 \\
Fraction of $<1$ & 0.96 & 0.85 & 0.70 & 0.85 & 0.85 & 0.78 \\
Fraction of signif. $<1$ & 0.33 & 0.22 & 0.19 & 0.19 & 0.22 & 0.26 \\
\hline & \multicolumn{5}{c|}{ Price level } \\
\hline Median value & 0.98 & 0.98 & 0.97 & 0.98 & 0.97 & 0.98 \\
Fraction of $<1$ & 0.70 & 0.78 & 0.81 & 0.70 & 0.63 & 0.63 \\
Fraction of signif. $<1$ & 0.07 & 0.11 & 0.07 & 0.11 & 0.11 & 0.11 \\
\hline & \multicolumn{5}{c}{ Interest rate } \\
\hline Median value & 0.98 & 0.97 & 0.97 & 0.98 & 0.98 & 0.98 \\
Fraction of $<1$ & 0.78 & 0.81 & 0.81 & 0.70 & 0.70 & 0.67 \\
Fraction of signif. $<1$ & 0.15 & 0.15 & 0.15 & 0.15 & 0.15 & 0.11 \\
\hline
\end{tabular}

Notes: This table presents the RMSFE statistics of the JP + model relative to the NK model obtained in a Monte Carlo experiment in which the data are generated from the JP+ model with fixed parameters. The significance of differences in the RMSFEs is evaluated with the Diebold-Mariano test at $5 \%$ significance level. 


\section{Appendix}

\section{A.1 Data sources}

In our empirical analysis we use the following quarterly macroeconomic time series for the period 1975-2013:

- $\tilde{y}_{t}$ - GDP at constant prices divided by population (log); source: IFS, AWM (GDP) and AMECO (population)

- $\tilde{p}_{t}$ - CPI index (log); source: MEI and AWM

- $\tilde{i}_{t}$ - Short-term nominal money market rate; soure: IFS

- $\tilde{e}_{t}$ - nominal exchange rate against the USD (log), quarterly average; source: MEI, AWM

- $\tilde{s}_{t}$ - Terms of trade $(\log )$; source: IFS

- $\tilde{c a}$ - Current account balance to GDP ratio; source: MEI

- $\tilde{q}_{t}$ - CPI-based real effective exchange rate (log); source: calculated with $\tilde{p}_{t}$ and $\tilde{e}_{t}$.

Where applicable, data are seasonally adjusted using the Tramo/Seats procedure. The source acronyms indicate: MEI - Main Economic Indicators (OECD), IFS - International Financial Statistics (IMF), AWM - Area-Wide Model database (ECB), AMECO - AMECO database (European Commission).

Foreign variables $\tilde{y}_{t}^{*}, \tilde{p}_{t}^{*}$ and $\tilde{i}_{t}^{*}$ are constructed as weighted averages of respective indicators with weights that are based on effective exchange rates (EER) published by the Bank for International Settlements (Klau and Fung, 2006). More specifically, we compute the average values of EER weights over the period 1993-2010 and subsequently adjust them so that they sum to unity. The final weights and achieved coverage are

\begin{tabular}{|l|cccccc|c|}
\hline & Australia & Canada & UK & US & euro area & Japan & Coverage \\
\hline Australia &. & 2.4 & 8.8 & 32.5 & 30.2 & 26.1 & 74.3 \\
Canada & 0.3 &. & 2.5 & 81.5 & 9.6 & 6.1 & 90.8 \\
UK & 1.0 & 2.0 &. & 18.5 & 70.9 & 7.5 & 91.9 \\
\hline
\end{tabular}




\section{A.2 Measurement equations}

The following measurement equations link the model variables to the data described in the previous section

$$
\begin{gathered}
\tilde{y}_{t}-\tilde{y}_{t-1}=\mu_{y}+y_{t}-y_{t-1} \\
\tilde{p}_{t}-\tilde{p}_{t-1}=\mu_{\pi}+\pi_{t} \\
\tilde{i}_{t}=\mu_{i}+i_{t} \\
\tilde{q}_{t}-\tilde{q}_{t-1}=q_{t}-q_{t-1} \\
\tilde{c} a_{t}=\mu_{c a}+c a_{t} \\
\tilde{y}_{t}^{*}-\tilde{y}_{t-1}^{*}=\mu_{y}^{*}+y_{t}^{*}-y_{t-1}^{*} \\
\tilde{p}_{t}^{*}-\tilde{p}_{t-1}^{*}=\mu_{\pi}^{*}+\pi_{t}^{*} \\
\tilde{i}_{t}^{*}=\mu_{i}^{*}+i_{t}^{*} \\
\tilde{s}_{t}-\tilde{s}_{t-1}=s_{t}-s_{t-1}
\end{gathered}
$$

Note that we do not detrend or demean the data prior to estimation. Instead, we do it within the estimation procedure by including intercepts in the measurement equations wherever applicable.

All of these measurement equations are used in the JP+ variant, the JP model drops equation (A.9), LS does not include equations (A.6)-(A.9) and the NK variant uses only equations (A.1)-(A.3).

\section{A.3 Calibration and prior assumptions}

As Justiniano and Preston (2010b), we calibrate $\beta$ to 0.99 and $\chi$ to 0.01 . We also fix $\alpha$ to 0.14 for Australia, 0.18 for Canada and 0.19 for the UK. These numbers correspond to these countries' average GDP shares of exports and imports, corrected for the import content of exports estimated by the OECD.

The remaining parameters are estimated using Bayesian methods implemented in Dynare. The prior assumptions for structural parameters are the same as in Justiniano and Preston (2010b). The prior distributions for the constants in measurement equations are assumed to be uniform over intervals wide enough to ensure their uninformativeness. 